\title{
WHEN A LIFE SAVING PROCEDURE BECOMES LIFE THREATENING
}

\author{
MORSHED MG ${ }^{1}$, ZAHIRUDDIN $\mathrm{M}^{2}$, TARANNUM $\mathrm{S}^{3}$, , SARKER $\mathrm{S}^{4}$, ISLAM AKMA ${ }^{5}$
}

\begin{abstract}
Most of the hospitalized patients are anaemic to some degree in our country and sometimes need blood transfusion. Complications of blood transfusion are rare but can be life-threatening. Since 2005, it has been a legal requirement that all serious adverse reactions attributable to the safety or quality of blood transfusion are reported. Most reported complications are because of transfusion of mismatched blood products and are avoidable with proper vigilance. A 45 year old female who underwent salpingo-oophorectomy with total abdominal hysterectomy for torsion of ovarian cyst and was transfused one unit of blood peroperatively. Blood grouping was accidentally incorrect and cross matching was not done. This mismatched blood transfusion resulted in acute renal failure. Patient was referred from the private hospital to Dhaka Medical College Hospital, Dhaka and was managed by forced alkaline diuresis and later, haemodialysis.
\end{abstract}

Key words: Mismatched blood transfusion, haemolytic transfusion reaction,

J Dhaka Med Coll. 2010; 19(2) : 154-157.

\section{Introduction:}

In Bangladesh, anaemia is a major public health issue ${ }^{1}$. The study of red blood cell antigens and antibodies form the foundation of transfusion medicine. Adverse reactions to transfused blood components occur in spite of multiple tests, inspections and checks. Those due to $\mathrm{ABO}$ incompatibility are the most fatal ones. Acute haemolytic transfusion reaction is immune mediated, mostly due to ABO incompatibility and rare with an incidence of $1: 12000$ and fatal reactions have an incidence of $1: 100,000 .^{2}$ A haemolytic transfusion reaction has been defined by Mollison as "the occurrence of signs of red cell destruction following transfusion, the most obvious of these signs being haemoglobinuria and jaundice'. ${ }^{3}$ Haemolytic reaction is the most important complication of blood transfusion and together with circulatory overload is responsible for most fatalities. Acute hemolytic reactions are responsible for significant morbidity and mortality and may lead to life-threatening shock, disseminated intravascular coagulation (DIC), and renal failure. ${ }^{4}$
The incidence of mismatched blood transfusion is quite rare. In the UK, a total of 1279 cases were reported in 2009 on incorrect blood component transfused (IBCT). 282 true IBCT events occurred among which there were 14 incompatible ABO transfusions in 2009. Ten of these cases arose from bedside administration errors, 2 from wrong blood in tube phlebotomy errors and 2 from laboratory errors. There were no deaths directly caused by transfusion but 3 patients died following reactions that were considered to have contributed to their deaths. There were also 3 cases of major morbidity resulting from $\mathrm{ABO}$ incompatibility. ${ }^{5}$ Group $\mathrm{O}$ patients are especially liable to severe reactions. ${ }^{5}$ Mismatching was due to an error in the grouping of blood which was not matched against donor blood. Women are twice as likely to have a haemolytic reaction to an incorrect transfusion. ${ }^{6}$

\section{Case summary:}

A 45 year old female was admitted into a private hospital with the complaints of severe lower

1. Dr. Md. Golam Morshed, Assistant Registrar, Department of Medicine, Dhaka Medical College Hospital, Dhaka.

2. Dr. Mohammad Zahiruddin, Associate Professor, Department of Medicine, Dhaka Medical College \& Hospital, Dhaka.

3. Dr. Sanjana Tarannum, Intern Doctor, Department of Medicine, Dhaka Medical College Hospital, Dhaka.

4. Dr. Shaymal Sarker, Associate Professor, Department of Medicine, Dhaka Medical College \& Hospital, Dhaka.

5. Dr. AKM Aminul Islam, Registrar, Department of Medicine, Dhaka Medical College Hospital, Dhaka.

Correspondence: Dr. Md. Golam Morshed, Assistant Registrar, Department of Medicine, Dhaka Medical College Hospital, Dhaka. E-mail: morshed123@yahoo.com 
abdominal pain and was diagnosed as a case of torsion of left ovarian cyst. Preoperative routine investigations showed haemoglobin $11.2 \mathrm{gm} /$ $\mathrm{dl}$, serum bilirubin $0.52 \mathrm{mg} / \mathrm{dl}$ and her routine urine examination was normal. Ultrasonogram of whole abdomen showed a large cystic lesion of about $15.8 \mathrm{~cm} \mathrm{x} 14.7 \mathrm{~cm}$ in size on left side of lower abdomen extending up to left lumbar region and markers of ovarian malignancy (CA125 and CA-19.9) were within normal limit. Her blood group was detected $A B$ positive. The following day, she underwent laparotomy followed by total abdominal hysterectomy with left sided salpingo-oophorectomy under spinal anaesthesia. During the operation one unit of blood was transfused. Half an hour after operation the attending physician noticed no urine output of this patient and only $150 \mathrm{ml}$ blood was collected in the drain tube bag. Her pulse was 80 beats/minute, blood pressure was $90 / 70 \mathrm{~mm} \mathrm{Hg}$, respiratory rate was 24 breaths $/$ min. She was advised for renal function test. The attending laboratory technician noticed haemolysed blood in the sample collected for renal function test. Then she was advised for estimation of unconjugated serum bilirubin and haemoglobin. Her haemoglobin level was $5.4 \mathrm{mg} / \mathrm{dl}$, serum creatinine was $4.5 \mathrm{mg} / \mathrm{dl}$ and unconjugated serum bilirubin was $4.6 \mathrm{mg} / \mathrm{dl}$. The patient was suspected to develop acute renal failure following mismatched blood transfusion and was referred to Dhaka Medical College Hospital (DMCH) for better management. On her admission into $\mathrm{DMCH}$, the patient was anaemic, icteric with no oedema. Her pulse was $80 / \mathrm{min}$, blood Pressure was $140 / 90 \mathrm{~mm} \mathrm{Hg}$ and temperature was normal. Blood grouping was done and found $\mathrm{O}$ positive. The patient was immediately given 2 litres of 5\% DNS and $80 \mathrm{mg}$ IV frusemide and then $40 \mathrm{mg}$ IV twice daily. On laboratory evaluation, her haemoglobin was $6.5 \mathrm{~g} / \mathrm{dl}$, platelet count was $190 \times 10^{9} / \mathrm{L}$, serum bilirubin was $3.68 \mathrm{mg} / \mathrm{dl}$, serum creatinine was $2.34 \mathrm{mg} /$ $\mathrm{dl}$ and serum $\mathrm{Na}^{+}, \mathrm{K}^{+}, \mathrm{Cl}^{-}$and $\mathrm{HCO}_{3}{ }^{-}$were 139 , 3.34, 134 and $21 \mathrm{mmol} / \mathrm{L}$ respectively. Serum lactate dehydrogenase (LDH) was raised to 948 IU/L. Urinary haemoglobin was significantly elevated. The second day she was given one unit of whole blood transfusion. Intake of fluid was restricted. Forced alkaline diuresis was done with IV sodium bicarbonate $50 \mathrm{ml}$ i.v. in a static dose and $25 \mathrm{ml} 8$ hourly. Urine output was $190 \mathrm{ml}$ in 24 hours. Serum creatinine became elevated to $5.8 \mathrm{mg} / \mathrm{dl}$, reticulocyte count was $2 \%$ and D dimer was raised to $1000 \mathrm{ng} / \mathrm{ml}$. On the third day, her pulse was 72 beats $/ \mathrm{min}$, blood pressure was $140 / 90 \mathrm{~mm} \mathrm{Hg}$, haemoglobin was $7.4 \mathrm{~g} / \mathrm{dl}$, serum creatinine was $7.3 \mathrm{mg} / \mathrm{dl}$, $\mathrm{HBsAg}$ and Anti HCV were negative. She underwent haemodialysis for 2 hours with bicarbonate/acetate type fluid. Haemodialysis was given 7 times and was transfused with 3 units of compatible blood. However, she developed septicaemia with high WBC counts and her serum creatinine reached a static around $4.1 \mathrm{mg} / \mathrm{dl}$. She was under an antibiotic coverage and her urine output gradually increased and she entered the diuretic phase, which heralded her recovery.

\section{Discussion:}

The course of a severe immediate haemolytic reaction is typically characterized by four phases: the phase of haemolytic shock, the post-shock phase in which the clinical features of increased blood destruction become obvious, the oliguric phase and the diuretic phase. ${ }^{3}$

In phase-I, typical symptoms are an aching pain in the lumbar region, sometimes in the thighs and down the legs, flushing of the face, throbbing in the head, anxiety, precordial pain or constriction, breathlessness, nausea, vomiting, chills, a rise in temperature, tachycardia, and a fall in blood pressure. Occasionally, the picture resembles anaphylactic shock with profound hypotension and peripheral circulatory failure. There is sometimes a feeling of heat along the vein into which the blood is being transfused. In about 50 percent cases, DIC develops which is typically characterized by persistent oozing from the surgical field and from venepunctures; it commonly lasts for several days and sometimes reaches serious or even fatal proportions. In patients under anaesthesia, the haemolytic reaction is masked; however the possibility of such a reaction in a transfused anaesthetized patient should be considered, if one or more of the following develop without 
obvious reason: a sharp rise in pulse rate, a fall in blood pressure, flushing, sweating, or bleeding which is difficult to control. Morphine may also modify or mask a haemolytic reaction.

In phase-II, haemoglobinuria and jaundice become obvious. Haemoglobinuria is usually obvious in the first specimen of urine passed. Jaundice develops in about 12 hours and persists for several days, commonly being deepest on the day after transfusion. The haemoglobin level falls in proportion to the amount of blood destroyed. Red cell agglutination may be present on the blood film, and a moderate leucocytosis is usual.

In phase-III, kidneys may be damaged in many patients due to acute tubular necrosis. Oliguria is the first sign of renal failure and is accompanied by progressive azotaemia. The oliguric phase usually lasts for 6-12 days but may persist for up to three weeks or even longer. Complete anuria may develop, but it is uncommon.

In phase-IV, the end of the oliguric phase is marked by a spontaneous dieresis. Occasionally, there is a sudden massive diuresis but more commonly, there is a gradual increase of urinary output by $200-300 \mathrm{ml}$ per day. The diuretic phase usually heralds recovery.

A number of immediate investigations are recommended to detect haemolysis, to detect the cause of haemolysis (e.g. incompatibility) and to detect the complications of haemolysis. ${ }^{7}$ Firstly, to detect the presence of haemolysis a visual examination of the patient's plasma and urine (or assay of the haemoglobin level in plasma and urine) can be done. Peripheral blood film showing spherocytosis and red cell fragmentation as well as raised serum bilirubin and LDH levels indicate haemolysis. Secondly, to detect incompatibility of blood transfusion rechecking the documents, repeating the blood grouping of the patient and of the donor unit, screening patient's blood for anti red cell antibodies and Direct Agglutination Test (DAT) of patient's blood are recommended. Two of the major complications of incompatible blood transfusion are dessiminated intravascular coagulation (DIC) and acute renal failure. A total blood count with a blood film, coagulation profile and fibrin degradation products (or D-dimers) are required to diagnose DIC. On the other hand, renal function can be assayed with a blood urea, serum creatinine and a serum electrolytes level. Direct proof of intravascular haemolysis requires demonstration of one or more of the following: haemoglobinaemia, methaemalbuminaemia or haemoglobinuria. ${ }^{2}$ A raised serum bilirubin in a patient with a previously normal bilirubin is strong presumptive evidence of haemolysis. Transfusion of ABO-incompatible cells usually results from an identification error. This can occur at point of blood sampling and labelling (wrong blood in tube), laboratory testing (technical error), blood unit labelling (administrative error), and collection from the blood refrigerator or inadequate bedside checking. If red cells are mistakenly transfused to the wrong patient, there is approximately a 1 in 3 chance that $\mathrm{ABO}$ incompatibility will occur. The reaction is most severe if group A blood is transfused to a patient who is group O. ${ }^{8}$ The severity of acute haemolytic transfusion reaction (AHTR) depends on the degree of incompatibility, the amount of blood given, the rate of administration, and the integrity of the kidneys, liver, and heart. ${ }^{9}$ In our case, the acute haemolytic reaction presented with haemoglobinuria, constrictive chest pain and jaundice. Most of the signs and symptoms of acute hemolytic reaction was absent as the patient was under anaesthesia. Also oozing of blood and features of DIC were absent. The primary investigations showed a rise in serum bilirubin level, a fall in haemoglobin level and a rapid rise in serum creatinine. These were strongly suggestive of a haemolytic reaction as well as acute kidney injury. Later haemoglobinuria was found which indicated intravascular haemolysis. ${ }^{3}$ LDH levels were raised indicating breakdown of RBCs. Due to lack of affordability; some tests were delayed and might have not portrayed the real picture. Among these were the reticulocyte count and the Coomb's test. Reticulocyte count was not raised and Coomb's test was negative. As a postoperative complication, the patient also developed septicaemia. So, the raised D-dimer 
level could have been a marker of DIC or the septicaemia.

According to standard management protocols, monitoring the patient's vital signs before and during the transfusion is important to identify reactions promptly. There are strong reasons to believe that risk of serious consequences is proportional to the volume of incompatible blood transfused. ${ }^{10}$ When acute haemolysis is suspected, the transfusion must be stopped immediately, intravenous access maintained, and the reaction reported to the blood bank. A correctly labelled post transfusion blood sample and any untransfused blood should be sent to the blood bank for analysis. ${ }^{2}$ Intravenous fluids were administered cautiously (to avoid circulatory overload in the anuric patient). It is important to correct any pre-existing anaemia by transfusion of plasma, albumin, or compatible blood. Dextran should be avoided because of the risk of haemorrhagic complications. ${ }^{11}$ The patient was given compatible blood transfusions to correct the haemoglobin level. Forced alkaline diuresis was done for 2 days till haemodialysis facilities were available. Successful treatment of mismatched blood transfusion by alkalinization of urine with sodium bicarbonate was carried out in the 1920s for blackwater fever where there was similar blockage of the renal tubules with haematin. ${ }^{12}$ Corticosteroids are of no value in the immediate or subsequent treatment of a haemolytic transfusion reaction. ${ }^{11}$ Concomitant treatment of septicaemia with intravenous broad spectrum antibiotics resulted in clinical improvement of the patient.

\section{Conclusion:}

The main risk of a blood transfusion is that the wrong blood type may be accidentally given. This happens about once in every 14,000 transfusions and about 20 people die yearly in the US from AHTR. ${ }^{13}$ It commonly results from clerical errors that are preventable with stringent checking. ${ }^{14}$ The surest way to avoid mismatched blood transfusions is to cross match blood before transfusing and to maintain constant strict clinical vigilance. Guidelines for compatibility procedures in blood transfusion laboratories are available now. ${ }^{15}$

It is recommended for meticulous vigilance by clinical personnel to identify mismatched blood transfusion reaction and immediate notification to the authorities. A total estimate of the number of such reactions in the country annually will help the health professionals to appreciate the magnitude of this fatal problem. A little diligence on our parts may outweigh the risks to the benefits of blood transfusion.

\section{References:}

1. Ahmed F. Anaemia in Bangladesh: a review of prevalence and aetiology. Public Health Nutr. 2000; 3(4): 385-93.

2. Fauci AS, Braunwald E, Kasper DL, Hauser SL, Longo DL, Jameson JL, et al. eds. Harrison's principles of internal medicine, $17^{\text {th }}$ ed. New York: McGraw-Hill; 2008. p. 2378-90.

3. Firkin F, Chesterman C, Penington D, Rush B. eds. DeGruchy's clinical haematology in medical practice, $5^{\text {th }}$ ed. New Delhi: Thomson Press; 1991. p. 482-5.

4. Capon SM, Sacher RA. Analytic reviews: hemolytic transfusion reactions: a review of mechanisms, sequelae and management. J Intensive Care Med. 1989; 4(3): 100-11.

5. Serious hazards of transfusion (SHOT). Annual Report 2009 Summary. Manchester Blood Centre, Manchester: 2009. Available from: http:// www.shotuk.org/wp-content/uploads/2010/06/ SHOT-2009-Summary.pdf [Accessed on 21.09.2010].

6. Myhre BA. Fatalities from blood transfusion. JAMA. 1980; 244(12): 1333-5.

7. Lewis SM, Bain BJ, Bates I. eds. Dacie and Lewis Practical haematology. $10^{\text {th }}$ ed. London: Churchill Livingstone; 2000.

8. Boon NA, Colledge NR, Walker BR, Hunter JAA. eds. Davidson's principles and practice of medicine. $20^{\text {th }}$ ed. Elsevier Churchill Livingstone; 2006. p.1021-3.

9. Sarode R. The Merck Manuals Online Medical Library: for health care professionals. Complications of transfusion. [Updated Nov. 2006; cited $21^{\text {st }}$ Mar. 2010]. Available from: http:// www.merck.com/mmpe/print/sec11/ch 146/ ch146e.html [Accessed on 21.09.2010].

10. Brzica S. Complications of transfusion. Int Anesthesiol Clin. 1982; 20: 171-93.

11. Touey GH. Management of haemolytic transfusion reactions (Editorial). Vox Sang. 1963; 8(3): 257-61.

12. Baker SL, Dodds EC. Mismatched blood transfusion. JAMA. 1951; 146 (11): 1063.

13. Goodnough LT, Shander A, Brecher ME. Transfusion medicine: looking to the future. Lancet. 2003; 361(9352): 161-9.

14. Pineda AA, Brzica SM, Jr., Taswell HF. Hemolytic transfusion reaction: recent experience in a large blood bank. Mayo Clin Proc. 1978; 53(6): 378-90.

15. Working party of the British Committee for standards in Haematology Blood Transfusion Task Force. Guidelines for compatibility procedures in blood transfusion laboratories. Transfusion Medicine. 2004; 14(1): 59-73. 